\title{
Energetics of Larval Swimming and Metamorphosis in Four Species of Bugula (Bryozoa)
}

\author{
DEAN E. WENDT* \\ Department of Organismic and Evolutionary Biology, Harvard University, \\ Cambridge, Massachusetts 02138
}

\begin{abstract}
The amount of energy available to larvae during swimming, location of a suitable recruitment site, and metamorphosis influences the length of time they can spend in the plankton. Energetic parameters such as swimming speed, oxygen consumption during swimming and metamorphosis, and elemental carbon and nitrogen content were measured for larvae of four species of bryozoans, Bugula neritina, B. simplex, B. stolonifera, and B. turrita. The larvae of these species are aplanktotrophic with a short free-swimming phase ranging from less than one hour to a maximum of about 36 hours. There is about a fivefold difference in larval volume among the four species, which scales linearly with elemental carbon content and, presumably, with the amount of endogenous reserves available for swimming and metamorphosis. Mean larval swimming speeds (in centimeters per second) were similar among species. Specific metabolic rate and larval size were inversely related. For larvae of a given species, respiration rates remained similar for swimming and metamorphosis; however, because metamorphosis lasts about twice as long as a maximal larval swimming phase, it was more energetically demanding. Larger larvae expended more energy to complete metamorphosis than did smaller larvae, but in terms of the percentage of larval energy reserves consumed, swimming and metamorphosis were more "expensive" for smaller larvae. A comparison of the energy expended during larval swimming calculated on the basis of oxygen consumption and on the basis of elemental carbon decrease suggests that larvae of Bugula spp. may not use significant amounts of dissolved organic material (DOM) to supplement their endogenous energy reserves.
\end{abstract}

\section{Introduction}

The larval life of many marine invertebrates is characterized by three distinct phases. The first, a swimming phase, is both a means of dispersal and, in planktotrophic larvae, a time to sequester the energy needed for larval development and metamorphosis. The two subsequent phases-settlement and metamorphosis - can be temporally distinct, as in some echinoderm larvae (e.g., Strathmann, 1974), or tightly coupled, as in bryozoan larvae (e.g., Ryland, 1974). That the duration of the larval swimming phase can have detrimental effects on the latter two phases of the life cycle has been demonstrated for several species in at least three phyla, including bryozoans (Nielson, 1981; Woollacott et al., 1989; Orellana and Cancino, 1991; Hunter and Fusetani, 1996; Wendt, 1996), barnacles (Pechenik et al., 1993), and polychaetes (Qian et al., 1990; Pechenik and Cerulli, 1991). In fact, an increased larval swimming phase can have longterm costs to adult growth and reproduction in bryozoans (Wendt, 1998). Effects associated with increased swimming duration are common, but not universal. For example, Highsmith and Emlet (1986) found no significant correlation between "delay time" and juvenile growth rate in the sand dollar Echinarachnius parma, which has planktotrophic larvae. For aplanktotrophic larvae, depletion of energetic reserves during larval swimming has been suggested to be responsible, at least in part, for the observed costs to later phases of the life cycle (Lucas et al., 1979; Jaeckle, 1994; Pechenik, 1990; Pechenik and Fried, 1995; Wendt, 1996; Jarrett and Pechenik, 1997; Pechenik et al., 1998).

Energy needed to sustain the three phases of larval existence is provided by a maternal source, by larval feeding while in the plankton (with relatively little maternal input), by uptake and utilization of dissolved organic materials (DOM), or by some combination of these sources (for a recent review of the developmental modes of marine inver- 
tebrate larvae, see Levin and Bridges, [1995]). Regardless of the source, larval energy reserves must be sufficient to allow for dispersal (swimming phase), location of a suitable recruitment site (settlement phase), and transformation from larva to adult (metamorphic phase). The energy available for these processes in part influences the length of the dispersal and settlement phases (Crisp, 1974; Lucas, 1979; Pechenik, 1980, 1990; Richmond, 1987, 1988; Jaeckle, 1994; Shilling and Manahan, 1994; Zaslow and Benayahu, 1996; Hoegh-Guldberg and Emlet, 1997; Wilson and Harrison, 1998).

Metabolic costs are generally believed to be inversely related to animal size. For example, the theoretical cost of motility for small $(<1 \mathrm{~mm})$, ciliated animals and protozoans is inversely related to size and positively related to swimming speed (Crawford, 1992). That is, for a given swimming speed, the theoretical cost of transport is greater for smaller organisms. Additionally, body size and mass-specific basal metabolic rate are known to have an inverse relationship (Zeuthen, 1947, 1953). Based on these relationships, and assuming energy content is proportional to larval size, smaller larvae will have less energy to meet higher metabolic and locomotory costs. This situation raises some interesting questions about the energetics of swimming and metamorphosis as it is related to larval size. Does it in fact cost smaller larvae more to swim and metamorphose? If it does: Do smaller larvae swim slower to offset the increased energetic cost? Does the cost of metamorphosis decrease proportionately to offset the increased cost of swimming? Are the effects of increased swimming duration incurred sooner in smaller larvae?

The four bryozoans used in this study, Bugula neritina, $B$. simplex, B. stolonifera, and B. turrita, are ideal for energetic studies for several reasons: (1) Larvae are liberated synchronously and often in large quantities from adult colonies; thus, the larvae in a batch released at the same time are similar in age. (2) The larval swimming phase is shortranging from minutes to tens of hours - and the length of the swimming phase can be readily prolonged using bright illumination and curtailed using elevated concentrations of exogenous KCl. (3) The size range of larvae among species is large, larvae are similar morphologically, and the adult colonies occupy similar ecological niches in that they are all common members of fouling communities. (4) Larval development, physiology, and anatomy are similar among the species. Embryonic stages of Bugula spp. are brooded on the adult colony in specialized structures called ovicells (Woollacott and Zimmer, 1972). The larvae are aplanktotrophic (nonfeeding), receiving nutrients translocationally via a placenta-like organ during embryogenesis (Woollacott and Zimmer, 1975). The larvae lack a digestive tract and have no coelomic and blastocoelic cavities (Woollacott and Zimmer, 1978). Most individuals are positively phototactic on release, becoming photonegative after the first several hours of larval swimming (Pires and Woollacott, 1997; Wendt and Woollacott, 1999). Metamorphosis begins with the eversion of the internal sac, which attaches the larva to the substratum. The first part of metamorphosis involves a rapid and cataclysmic reorganization of larval tissues, followed by differentiation of these tissues into adult structures (Woollacott and Zimmer, 1971, 1978; Reed and Woollacott, 1982, 1983). Thus, these species provide an elegant system in which to examine the relationship between larval size and the energetic costs of swimming and metamorphosis.

The present study was undertaken to compare the relative proportion of larval energy reserves used during swimming and metamorphosis, and to examine the relationship between larval size and several energetic parameters such as larval energy content and the energetic costs during swimming and metamorphosis. The following measurements were made: (1) larval size and swimming speeds for each of the four species; (2) oxygen consumption, and hence larval energy expenditure, during swimming and metamorphosis for each of the four species; and, (3) the amounts of carbon and nitrogen in newly released larvae compared to amounts in those swimming for $24 \mathrm{~h}$, an additional estimation of energy expenditure during swimming.

\section{Materials and Methods}

\section{Collection and maintenance of adults}

Sexually mature colonies of Bugula neritina were collected from floating docks on the Indian River in Fort Pierce, Florida, during March 1997 and from Duke University Marine Laboratory in Beaufort, North Carolina, during May 1998. Colonies of B. simplex, B. stolonifera, and B. turrita were collected from floating docks on Eel Pond in Woods Hole, Massachusetts, during July and August, 1996 and 1997. Colonies collected in Florida were maintained at the Smithsonian Marine Station at Link Port (Fort Pierce) in plastic boxes that were continuously supplied with seawater. North Carolina and Woods Hole colonies were maintained at Harvard University in plastic aquaria. Colonies remained in the dark and received no supplemental food.

\section{Larval release and swimming}

Larvae for each experiment were obtained from several colonies to foster genetically heterogeneous populations. Parent colonies used for experiments were kept in the laboratory less than 5 days. Colonies were removed from the dark, placed in glass bowls with 1.01 of seawater, and then exposed to fluorescent light. Larvae appeared within $10 \mathrm{~min}$ of illumination, and release was complete by $1 \mathrm{~h}$. As most larvae of Bugula spp. are positively phototactic on release, they aggregated at the illuminated side of dishes, a behavior that facilitated collection. Both colonies and larvae appeared healthy throughout the 5-day experimental period. In 
fact, colonies continued to release larvae for several days afterward.

In experiments that required increased duration of larval swimming, larvae were transferred to an autoclaved 1.5-1 glass finger bowl containing about 1.01 of $0.2-\mu \mathrm{m}$ filtered seawater. Larvae were prevented from initiating metamorphosis by continuous exposure to bright, fluorescent illumination accompanied by stirring (Wendt, 1996). The bowl was placed on an acrylic plastic table to reduce UV exposure and illuminated from below by three 20-W, 36-inch, full-spectrum Vite-lite lamps. Pieces of aluminum foil were arranged around the finger bowl to maintain constant levels of illumination from all directions. Illumination intensities ranged from 130 to $170 \mu \mathrm{E} \mathrm{m}^{-2} \mathrm{~s}^{-1}$. A fan was used to blow air between the lights and the table, which served to maintain ambient room temperature $\left(\mathrm{ca} .20^{\circ} \mathrm{C}\right)$ during larval swimming.

\section{Carbon and nitrogen analysis}

For each replicate sample, several hundred larvae were washed three times in autoclaved, $0.2-\mu \mathrm{m}$ filtered seawater. Seawater was filtered before autoclaving and again immediately before larval washings to remove any particulate organic material. After washing, batches of about 100 larvae were transferred to an Eppendorf tube and centrifuged for 10 min to "pellet" the larvae. This process did not disrupt larval tissues, and the larvae swam normally when the pellet was resuspended. The larval pellet was then transferred to tin capsules in about $100 \mu \mathrm{l}$ of seawater. The samples were dried overnight at $60^{\circ} \mathrm{C}$ and stored in a desiccator. Blank samples were prepared for each condition by transferring similar volumes of filtered seawater without larvae. The content of particulate organic nitrogen and carbon in samples was analyzed on a Europa Scientific Ltd. (Crewe, Lancashire, UK) model 20/20 mass spectrometer equipped with an automated Dumas combustion sample preparation system (model ANCA nt) in a continuous flow configuration (according to the method of McCarthy et al., [1999]). The system was calibrated with a peptone standard (Sigma Chemical). Amounts of carbon and nitrogen per larva were calculated by dividing the total amount in the sample by the number of larvae. All samples were blank corrected.

\section{Oxygen consumption of larvae and metamorphosing individuals}

The metabolic rate of individuals was measured as the rate of oxygen consumption at $20^{\circ} \pm 0.5^{\circ} \mathrm{C}$. Oxygen consumption rates were measured in a Strathkelvin model \# RC 300 respiration chamber that was connected to a recirculating water bath. A Strathkelvin model \# 1302 polarographic oxygen electrode served as the roof of chamber, which was connected to a Strathkelvin model \# 781 oxygen meter. For experiments in Fort Pierce, Florida, the analog output from the oxygen meter was converted to a digital signal and transferred to a computer using an analog/digital converter and the Datacan IV computer software package (Sable Systems, Inc.). For the experiments in Cambridge, Massachusetts, the meter was connected to an analog chart recorder. The voltage output for the sensor was calibrated for a zero value using an oxygen-free solution of $0.01 \mathrm{M}$ of disodium tetraborate and crystalline sodium sulfite. The voltage output at saturation was calibrated using seawater that was continuously bubbled for $30 \mathrm{~min}$ prior to the calibration. Saturation levels of oxygen for each experiment were calculated using the barometric pressure, vapor pressure, and standard values of oxygen solubility for water of a specific salinity and temperature (Weast and Astle, 1980). After each trial, the chamber and electrode membrane were swabbed with $70 \%$ ethanol and washed four times with $0.2-\mu \mathrm{m}$ distilled water. The rate of oxygen consumption per individual was calculated as the slope of the regression line for the trial, divided by the number of individuals present, multiplied by 60 (i.e., $\mathrm{V} \mathrm{O}_{2}$ consumed ind ${ }^{-1} \mathrm{~h}^{-1}$ ). Using the ideal gas law, this value was converted to $\mathrm{mol} \mathrm{O}_{2}$ ind $^{-1} \mathrm{~h}^{-1}$. All rates were corrected for self-consumption of the electrode. The rates of oxygen consumption were converted to energy units using an oxyenthalpic equivalent of $468 \mathrm{KJ}$ mol $\mathrm{O}_{2}{ }^{-1}$, which equals the average equivalent for protein $\left(527 \mathrm{KJ} \mathrm{mol} \mathrm{O}_{2}{ }^{-1}\right.$ ), lipid $\left(441 \mathrm{KJ} \mathrm{mol} \mathrm{O}_{2}{ }^{-1}\right)$, and carbohydrate $\left(473 \mathrm{KJ} \mathrm{mol} \mathrm{O}_{2}{ }^{-1}\right.$ ) (Gnaiger, 1983).

Respiration rates were determined for larvae of $B$. neritina, B. simplex, B. stolonifera, and B. turrita. On release, about 20 larvae were transferred in $300 \mu \mathrm{l}$ of $0.2-\mu \mathrm{m}$ filtered seawater to the respiration chamber. After a 20-min acclimation, the chamber was sealed and the rate of oxygen depletion was followed for $30 \mathrm{~min}$. The number of larvae was counted after each trial. Only larvae less than $4 \mathrm{~h}$ old were used.

Respiration rates during metamorphosis were determined for $B$. neritina, $B$. simplex, and B. stolonifera. Preliminary experiments demonstrated that $B$. turrita did not metamorphose normally under laboratory conditions, hence this species was not used. To determine oxygen consumption rates during metamorphosis, 30-min spot-measurements were taken on groups of 10-15 individuals during metamorphosis. The duration of metamorphosis was defined as the time from eversion of the larval metasomal sac to eversion of the lophophore of the ancestrular polypide. Larvae were placed in the tops of Beem capsules and exposed to $10 \mathrm{~m} M$ excess $\mathrm{KCl}$ in seawater to induce metamorphosis (Wendt and Woollacott, 1995). About 30 min after larvae initiated metamorphosis, the capsule tops were removed from the $\mathrm{KCl}$ solution and placed in finger bowls containing $200 \mathrm{ml}$ of $0.2-\mu \mathrm{m}$ filtered seawater. The finger bowls were covered and incubated at $20^{\circ} \mathrm{C}$. To minimize bacterial and protozoan growth, $50 \mu \mathrm{g} \mathrm{ml}^{-1}$ of penicillin and streptomycin B were added to the seawater (Strathmann, 1987). Preliminary ex- 
periments showed that metamorphosis proceeded at typical rates in the presence of antibiotics and all metamorphs appeared anatomically normal. The use of Beem capsule tops ensured that individuals were never exposed to air during transfer from the culture dish to the respirometry chamber and that respiration measurements were made on the same group of individuals throughout metamorphosis. All measurements were made in $600 \mu \mathrm{l}$ of $0.2-\mu \mathrm{m}$ filtered seawater and individuals were acclimated for 10-15 minutes before the chamber was sealed. The first measurement was taken less than $1 \mathrm{~h}$ after the onset of metamorphosis and then at 12-h intervals until metamorphosis was completed by more than half the individuals in a given trial.

\section{Initiation of metamorphosis as a function of swimming duration}

Larvae of $B$. stolonifera and B. turrita were released and kept swimming as described above. Immediately after release and at 12-h intervals for $36 \mathrm{~h}$, larvae were induced to metamorphose using $10 \mathrm{~m} M$ excess $\mathrm{KCl}$ in seawater. Three days ( $c a .72 \mathrm{~h}$ ) after initiation of metamorphosis, the number of individuals that completed metamorphosis was determined.

\section{Larval swimming speeds and larval size}

Swimming speeds and larval size were determined using a Motionscope high-speed video system (model HR500; Redlake Imaging Corporation) connected to a Zeiss photomicroscope III. Digital images were transferred to a videocassette recorder for later analysis. The monitor was calibrated with a stage micrometer, so that larval size and distance traveled could be measured directly. Larvae of Bugula spp. swim in a corkscrew path and thus have a vertical component in their horizontal trajectory. If a fixed bottom is used as a reference for distance traveled, the speed of the larva is underestimated because this method neglects the vertical distance covered in the spiral path. Use of high-speed video connected to a microscope allows very small portions of the animal's path to be isolated, thereby providing a more accurate estimate of swimming speed. To ensure the most accurate measurements, larval speeds were calculated only over distances where larvae remained in the same plane of focus (i.e., functionally traveling in a horizontal manner). Therefore, total error in the vertical path was only $50 \mu \mathrm{m}$, which is equal to the depth of field for the Zeiss 6.3 neofluor objective. All experiments were conducted at room temperature $\left(\mathrm{ca} .20^{\circ} \mathrm{C}\right)$ and at a constant level of illumination. Swimming speeds were measured in a circular chamber that was made by gluing a clear, acrylic cylinder onto a microscope slide. The chamber was open on top and had a diameter of $1.5 \mathrm{~cm}$, a height of $0.5 \mathrm{~cm}$, and a total volume of about $1 \mathrm{ml}$. Given the size of the larvae, it was calculated that the chamber was large enough to avoid any potential wall effects (Vogel, 1994), so long as swimming speeds were measured on larvae in the central portion of the chamber.

\section{Statistical analysis}

Between-species differences in swimming speeds and larval size were analyzed with a one-way factorial analysis of variance (ANOVA). Differences in oxygen consumption rates during metamorphosis were analyzed using a repeated measures ANOVA, since at 12-h intervals respiration rates were determined for the same group of individuals for each trial. A one-tailed Student's $t$ test was used to identify significant differences in carbon and nitrogen of newly released larvae and those swimming for $24 \mathrm{~h}$. All data are presented as means \pm the standard error (SE) unless otherwise indicated. Data did not differ from a normal distribution, and there was no heteroscedasticity between treatments, as judged by an equality of variance test ( $F$ test).

\section{Results}

\section{Oxygen consumption during larval swimming and metamorphosis}

Average rates of larval oxygen consumption were $175 \pm$ $25,192 \pm 38,213 \pm 46,249 \pm 49 \mathrm{pmol} \mathrm{O}_{2}$ ind $^{-1} \mathrm{~h}^{-1}$ for Bugula stolonifera, B. simplex, B. turrita, and B. neritina, respectively. Larval oxygen consumption rates were not significantly different between species (one-way ANOVA: $\mathrm{df}=3, \mathrm{SS}=32849, \mathrm{MS}=10949, F=0.68, P=0.57)$. Oxygen consumption rates during metamorphosis were relatively constant for $B$. neritina and $B$. simplex (repeated measures ANOVA: df $=3, \mathrm{SS}=136030, \mathrm{MS}=45343$, $F=1.9, P=0.14$ for $B$. neritina; $\mathrm{df}=3, \mathrm{SS}=11752$, $\mathrm{MS}=3917, F=0.481, P=0.70$ for $B$. simplex); whereas rates for $B$. stolonifera increased significantly during the last 12-24 h of metamorphosis (repeated measures ANOVA: $\mathrm{df}=3, \mathrm{SS}=40352, \mathrm{MS}=13540, F=10.0$, $P=0.003$ ) (Fig. 1).

\section{Carbon and nitrogen utilization}

For each species, elemental carbon content was significantly less in larvae that swam for $24 \mathrm{~h}$ than in newly released individuals (Table 1). Likewise, elemental nitrogen content was significantly less in larvae of $B$. simplex that swam for $24 \mathrm{~h}$ (Table 1). Larvae of B. stolonifera and $B$. turrita that swam for $24 \mathrm{~h}$ had significantly less elemental nitrogen compared to newly released larvae in three out of four trials (Table 1). For larvae of B. neritina, however, elemental nitrogen decreased significantly over $24 \mathrm{~h}$ in only one out of four trials. When all trials were combined for statistical analysis, elemental carbon was significantly less in batches of larvae swimming for $24 \mathrm{~h}$; nitrogen content declined significantly for all species except $B$. neritina. 


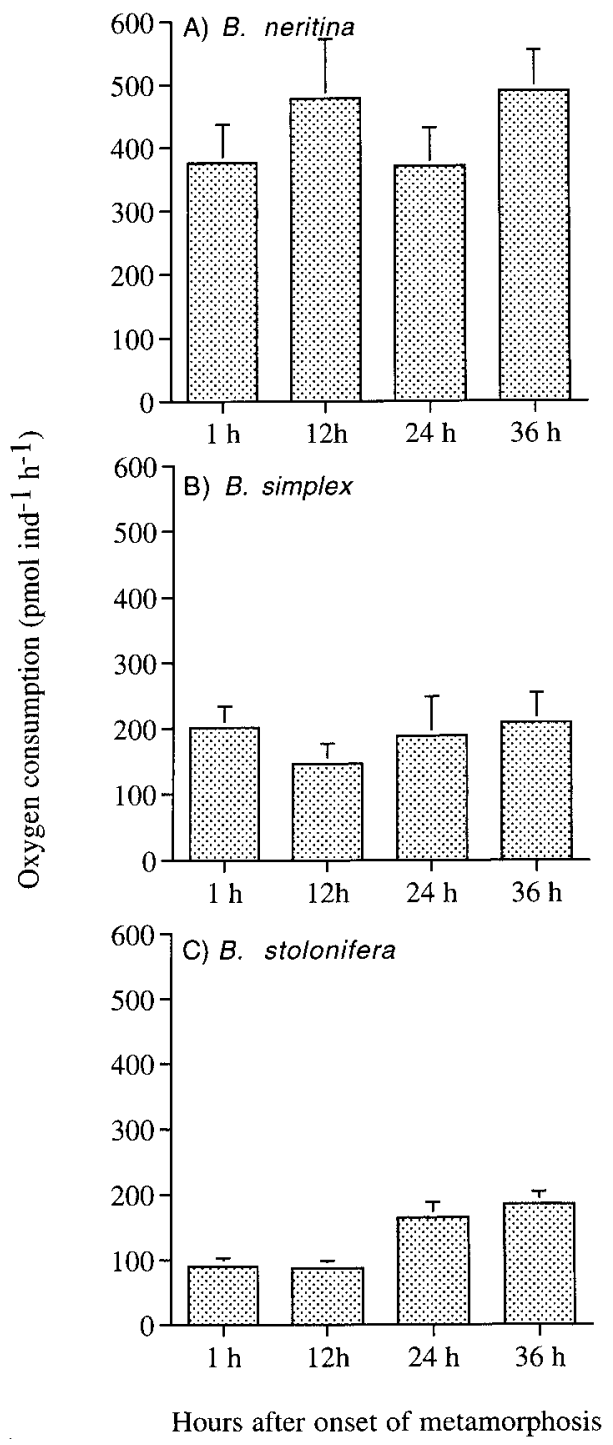

Figure 1. Rates of oxygen consumption $\left(20^{\circ} \mathrm{C}\right)$ at 12 -h intervals during metamorphosis for Bugula neritina, B. simplex, and B. stolonifera. Metamorphosis starts with eversion of the metasomal sac and concludes with eversion of the lophophore, the adult feeding structure. Metamorphosis was triggered using $10 \mathrm{mM}$ excess $\mathrm{KCl}$ in seawater. Because replicate trials contained several metamorphosing individuals ( $c$. 10-20), oxygen measurements were made until more than $50 \%$ of the individuals in a replicate completed metamorphosis. $n=5$ trials for each species. Bars $=$ 1 standard error

Mean protein content for newly released larvae $(<1 \mathrm{~h})$ was $0.25 \pm 0.02,0.47 \pm 0.02,0.67 \pm 0.03$, and $1.4 \pm 0.05 \mu \mathrm{g}$ larva $^{-1}$ for B. stolonifera, B. simplex, B. turrita, and $B$. neritina, respectively (calculated based on an elemental nitrogen conversion factor of 5.8 [Gnaiger and Bitterlich, 1984]).

\section{Completion of metamorphosis}

The ability to complete metamorphosis as a function of larval swimming duration was followed for $36 \mathrm{~h}$ for $B$. simplex and B. stolonifera. For the other two species, only about $60 \%$ of the larvae completed metamorphosis after $12 \mathrm{~h}$ of larval swimming (Fig. 2). After $24 \mathrm{~h}$ of larval swimming, only $30 \%$ of larvae of $B$. simplex and only about $2 \%$ of larvae of $B$. stolonifera completed metamorphosis.

\section{Larval size and parameters of larval swimming}

Mean swimming speeds were similar for larvae of all species. Consequently, speed, measured as body lengths per second, was inversely related to body size (Table 2). Bugula stolonifera, the smallest larva (mean length $=160 \pm 2 \mu \mathrm{m}$ ), swam at $0.49 \pm 0.01 \mathrm{~cm} \mathrm{~s}^{-1}$, traversing a distance equal to $31.0 \pm 0.8$ body lengths per second. In contrast, B. neritina, with the largest larvae (mean length $=271 \pm 2 \mu \mathrm{m}$ ), swam at $0.46 \pm 0.02 \mathrm{~cm} \mathrm{~s}^{-1}$, covering a distance equivalent to 17.2 body lengths per second. Bugula simplex and B. turrita, of intermediate size, covered intermediate distances (Table 2). Mean Reynolds numbers for larvae of each species ranged from $0.75 \pm 0.02$ for the smallest larvae $(B$. stolonifera $)$ to $1.20 \pm 0.03$ for the largest larvae $(B$. neritina) (Table 2).

\section{Discussion}

\section{Relationship between energetic parameters and larval size}

The amount of energy larvae possess determines, at least in part, the amount of time available for swimming and metamorphosis, and hence the ability to recruit to distant populations. On the basis of this relationship, one would predict that smaller larvae would lose the ability to successfully complete metamorphosis sooner than larger larvae. My data demonstrate this general relationship (Fig. 2).

Mean larval length and width varied by about $40 \%$ among the species of Bugula examined in this study (Table 2). This size difference translates into marked differences in larval volume and, therefore, in energy content (Table 1, Fig. 3). A similar relationship was found for echinoderms with lecithotrophic development (Jaeckle, 1995a). Carbon content spanned an order of magnitude between the smallest larva (B. stolonifera) and the largest larva (B. neritina) (Fig. 3, Table 1); and specific respiration rates declined exponentially with increasing carbon content (Fig. 4). Assuming that these larvae have finite energy reserves (ignoring the potential for DOM utilization [Jaeckle, 1994]), the specific respiration rates can be interpreted as a measure of how much energy is available for swimming and metamorphosis. Larvae of $B$. neritina, which are the largest, have the lowest respiration rates relative to their energy reserves, whereas larvae of B. stolonifera, which are the smallest, have the largest respiration rates relative to their energy reserves. The prediction is supported in that almost 50\% of the individuals of $B$. stolonifera and $B$. simplex lose 
Table 1

Comparison, for four species of Bugula, of elemental carbon and nitrogen content in newly released $(<1$ h) larvae and in larvae that had been swimming for $24 \mathrm{~h}$

\begin{tabular}{|c|c|c|c|c|c|c|}
\hline \multirow[b]{2}{*}{ Species } & \multicolumn{3}{|c|}{ Carbon (ng/larva) } & \multicolumn{3}{|c|}{ Nitrogen (ng/larva) } \\
\hline & $1 \mathrm{~h}$ & $24 \mathrm{~h}$ & $\Delta \mathrm{C}$ & $1 \mathrm{~h}$ & $24 \mathrm{~h}$ & $\Delta \mathrm{N}$ \\
\hline \multicolumn{7}{|l|}{ B. stolonifera } \\
\hline Trial $1(n=3,3)$ & $212 \pm 21$ & $120 \pm 14$ & -92 & $47 \pm 05$ & $29 \pm 03$ & -18 \\
\hline Trial $2(n=3,6)$ & $225 \pm 08$ & $181 \pm 06$ & -44 & $52 \pm 03$ & $50 \pm 01$ & $-2 *$ \\
\hline Trial $3(n=2,1)^{1}$ & $152 \pm 12$ & $106 \pm-$ & -46 & $34 \pm 03$ & $24 \pm-$ & -10 \\
\hline Trial $4(n=4,4)$ & $185 \pm 05$ & $126 \pm 12$ & -60 & $44 \pm 02$ & $29 \pm 03$ & -15 \\
\hline Mean of trials & $194 \pm 16$ & $134 \pm 16$ & $-60 \pm 10$ & $44 \pm 04$ & $33 \pm 06$ & $-11 \pm 04$ \\
\hline \multicolumn{7}{|l|}{ B. simplex } \\
\hline Trial $1(n=4,5)$ & $430 \pm 24$ & $358 \pm 16$ & -72 & $82 \pm 03$ & $67 \pm 03$ & -15 \\
\hline Trial $2(n=4,5)$ & $416 \pm 34$ & $345 \pm 19$ & -71 & $85 \pm 07$ & $70 \pm 04$ & -15 \\
\hline Trial $3(n=2,2)$ & $394 \pm 05$ & $282 \pm 08$ & -112 & $77 \pm 02$ & $54 \pm 01$ & -23 \\
\hline Mean of trials & $413 \pm 11$ & $329 \pm 23$ & $-85 \pm 14$ & $81 \pm 03$ & $64 \pm 05$ & $-17 \pm 03$ \\
\hline \multicolumn{7}{|l|}{ B. turrita } \\
\hline Trial $1(n=4,4)$ & $611 \pm 25$ & $503 \pm 33$ & -108 & $122 \pm 05$ & $103 \pm 06$ & -18 \\
\hline Trial $2(n=4,6)$ & $543 \pm 09$ & $484 \pm 15$ & -59 & $108 \pm 03$ & $100 \pm 03$ & $-8^{*}$ \\
\hline Trial $3(n=4,4)$ & $527 \pm 14$ & $431 \pm 25$ & -96 & $105 \pm 03$ & $87 \pm 05$ & -18 \\
\hline Trial $4(n=4,4)$ & $626 \pm 28$ & $542 \pm 10$ & -84 & $124 \pm 06$ & $111 \pm 03$ & -13 \\
\hline Mean of trials & $577 \pm 24$ & $490 \pm 23$ & $-87 \pm 11$ & $115 \pm 5$ & $100 \pm 05$ & $-14 \pm 03$ \\
\hline \multicolumn{7}{|l|}{ B. neritina } \\
\hline Trial $1(n=1,5)^{1}$ & $1334 \pm-$ & $1209 \pm 32$ & -125 & $270 \pm-$ & $242 \pm 07$ & -28 \\
\hline Trial $2(n=4,4)$ & $1340 \pm 52$ & $1207 \pm 12$ & -133 & $238 \pm 10$ & $237 \pm 04$ & $-1^{*}$ \\
\hline Trial $3(n=4,4)$ & $1333 \pm 54$ & $1215 \pm 34$ & -118 & $250 \pm 07$ & $237 \pm 08$ & $-14^{*}$ \\
\hline Trial $4(n=4,2)$ & $1245 \pm 32$ & $1129 \pm 19$ & -116 & $238 \pm 08$ & $222 \pm 15$ & $-15^{*}$ \\
\hline Mean of trials & $1313 \pm 03$ & $1190 \pm 03$ & $-123 \pm 04$ & $249 \pm 08$ & $234 \pm 05$ & $-15 \pm 03 *$ \\
\hline
\end{tabular}

Values are means plus or minus 1 standard error. Each replicate sample contained about 100 larvae; $n$ represents the number of replicates for newly hatched larvae $(1 \mathrm{~h})$ and for larvae that had swum for $24 \mathrm{~h}(24 \mathrm{~h})$. Carbon was significantly less in 24-h larvae in every trial $(P<0.05)$. For nitrogen, nonsignificant differences are marked with an asterisk (*).

${ }^{1}$ Statistical analysis was not possible due to lack of replicate samples in one treatment.

the ability to complete metamorphosis after a larval swimming period of $12 \mathrm{~h}$; in contrast, almost all individuals of $B$. neritina are able to complete metamorphosis after $12 \mathrm{~h}$ of larval swimming (Fig. 2). After $24 \mathrm{~h}$ of larval swimming, almost no individuals of $B$. stolonifera completed metamorphosis, but $25 \%$ of $B$. neritina and $B$. simplex larvae were still competent to metamorphose. Thus, in larvae of Bugula spp., energetic reserves apparently control the length of the competent period to some extent, as has been suggested for larvae of barnacles (Lucas et al., 1979; Jarret and Pechenik, 1997), corals (Richmond, 1987, 1988; Zaslow and Benayahu, 1996), bryozoans (Woollacott et al., 1989; Jaeckle, 1994; Wendt, 1996), and trematodes (Pechenik and Fried, 1995). In contrast, some authors have reported that energetic reserves do not strongly control the length of the competent period (Orellana et al., 1996; Wilson and Harrison, 1998). Thus, it appears that the amount of larval energy reserves in part controls the lengths of time larvae have to swim and metamorphose, but additional physiological factors may also be important for some species.

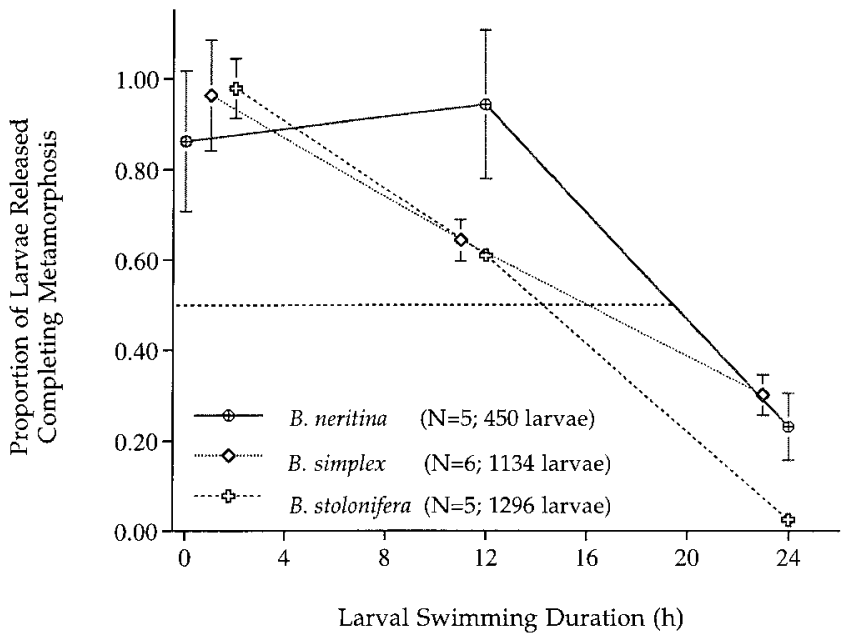

Figure 2. Loss of the ability to complete metamorphosis as a function of larval swimming duration for Bugula stolonifera and B. simplex. Larvae were released from parent colonies in bright illumination, which prevented them from metamorphosing. At 12-h intervals, samples of larvae were removed from the bright illumination and induced to metamorphose with $10 \mathrm{~m} M$ excess $\mathrm{KCl}$ in seawater. Data for B. neritina are from Wendt (1996). Bars $=95 \%$ confidence interval; $n=$ number of experimental trials. 
Table 2

Parameters used to calculate Reynolds numbers for larvae of Bugula spp.

\begin{tabular}{|c|c|c|c|c|c|c|}
\hline Species & $n$ & Length $(\mu \mathrm{m})$ & Width $(\mu \mathrm{m})$ & Velocity $\left(\mathrm{cm} \mathrm{s}^{-1}\right)$ & Body lengths $\mathrm{s}^{-1}$ & Reynolds Number ${ }^{1}$ \\
\hline B. stolonifera & 40 & $160 \pm 2$ & $142 \pm 2$ & $0.49 \pm 0.01$ & $31.0 \pm 0.8$ & $0.75 \pm 0.02$ \\
\hline B. simplex & 20 & $207 \pm 9$ & $201 \pm 8$ & $0.44 \pm 0.01$ & $24.5 \pm 1.0$ & $0.78 \pm 0.03$ \\
\hline B. turrita & 20 & $202 \pm 3$ & $196 \pm 2$ & $0.34 \pm 0.01$ & $19.2 \pm 0.5$ & $0.76 \pm 0.02$ \\
\hline B. neritina & 40 & $271 \pm 2$ & $231 \pm 2$ & $0.46 \pm 0.02$ & $17.2 \pm 0.7$ & $1.20 \pm 0.03$ \\
\hline
\end{tabular}

All values are means plus or minus 1 standard error.

${ }^{1}$ Reynolds numbers were calculated individually for each larva on the basis of swimming speed and larval size, then averaged.

\section{Metabolic cost of swimming and metamorphosis}

Clear trends in the metabolic costs of swimming and metamorphosis emerged within and between species of Bugula. For the species tested, the process of metamorphosis demanded markedly more energy than did a larval swimming duration of maximal length (Fig. 5). For example, individuals of $B$. neritina expended almost 4 times more energy during metamorphosis than they did for $20 \mathrm{~h}$ of swimming, which was considered a maximum swimming duration (estimated from Fig. 2). Larvae of B. stolonifera, the smallest larva, consumed approximately twice as much energy during metamorphosis as during a maximal swimming period of $16 \mathrm{~h}$ (estimated from Fig. 2). The metabolic cost of larval swimming was similar for each species, whereas the cost of metamorphosis was significantly higher for species with larger larvae. Metamorphosing individuals of $B$. neritina used approximately 4 times more energy to

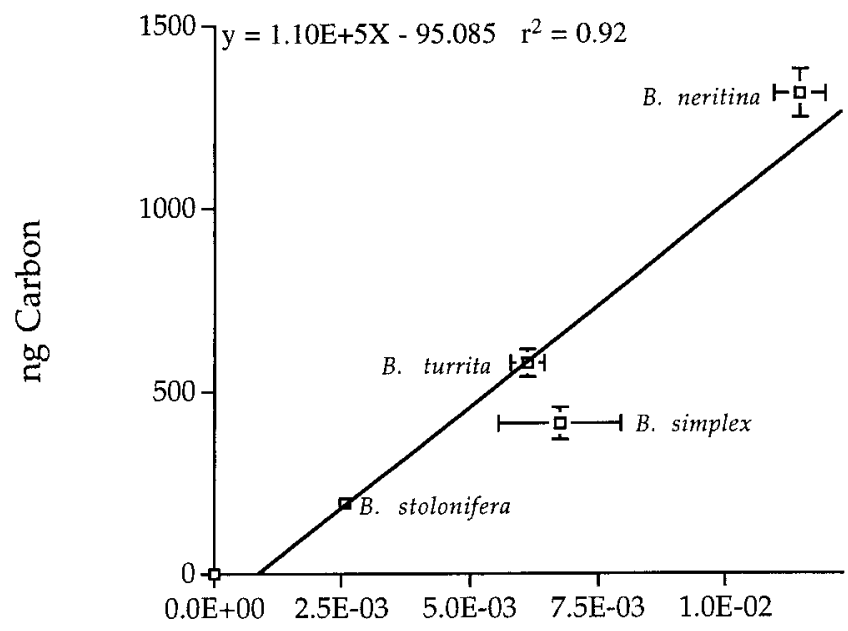

Volume $\left(\mathrm{mm}^{3}\right)$

Figure 3. Amount of elemental carbon as a function of larval volume for newly released larvae of Bugula neritina, B. simplex, B. stolonifera, and $B$. turrita. Volume was calculated using the formula for the volume of a cylinder $\left(\pi r^{2} h\right)$ based on the lengths $(h)$ and widths ( $r=0.5$ width) from Table 2. Error bars $=1$ standard deviation. complete metamorphosis than did those of $B$. stolonifera. However, when energy expenditure is normalized to endogenous energy reserves, smaller larvae actually expend more
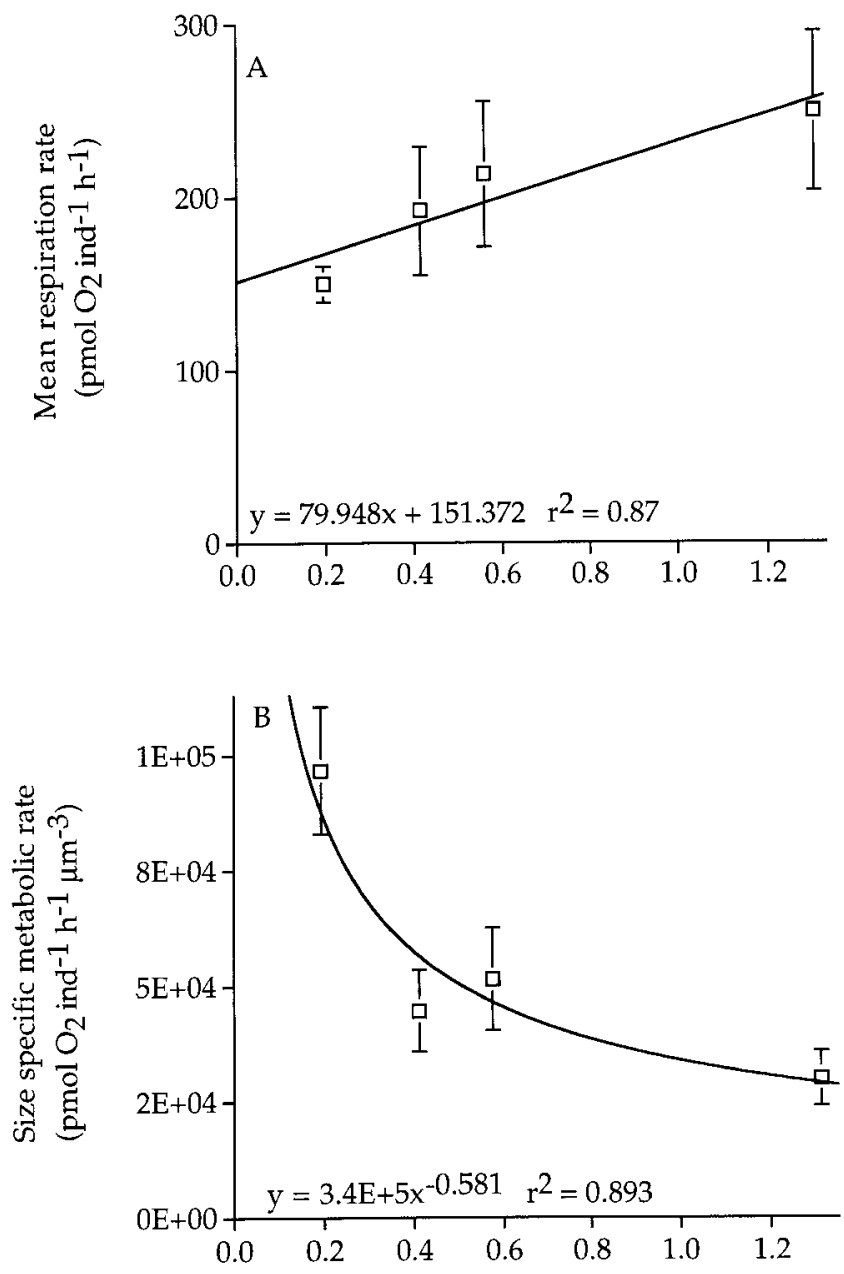

\section{Carbon $(\mu \mathrm{g})$}

Figure 4. (A) Metabolic rate as a function of larval carbon content ( $\mu \mathrm{g}$ C). (B) Specific metabolic rate $\left(\mathrm{pmol} \mathrm{O}_{2}\right.$ ind $\left.^{-1} \mathrm{~h}^{-1} \mu \mathrm{m}^{-3}\right)$ as a function of larval carbon content. Small larvae expended almost 4 times as much energy as a function of their endogenous energy reserves. Bars $=1$ standard error. 


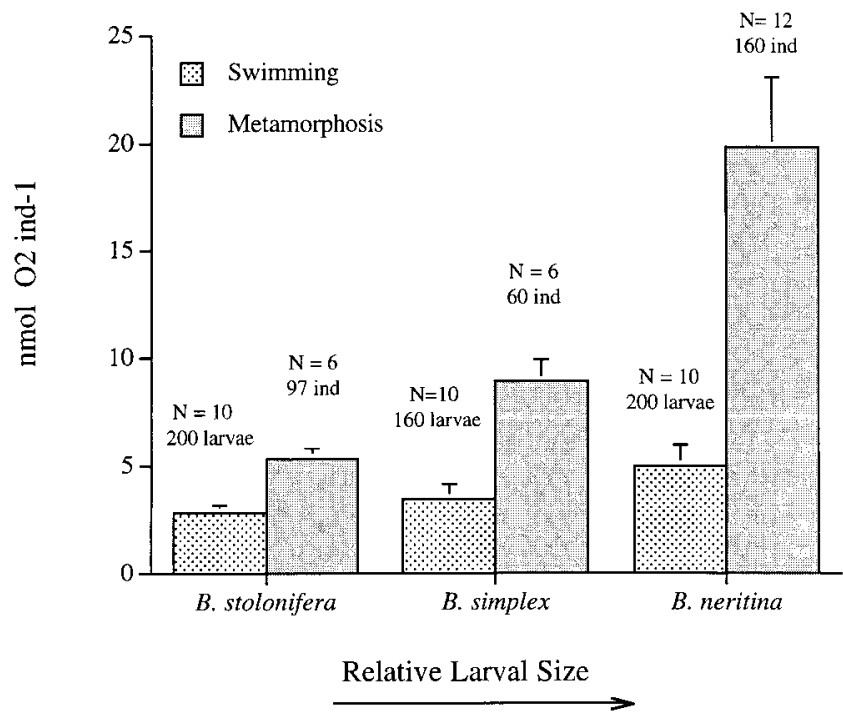

Figure 5. Metabolic cost of a maximum larval swimming phase compared with the overall metabolic cost of metamorphosis for larvae of Bugula neritina, B. simplex, and B. stolonifera. Total oxygen consumption for swimming and metamorphosis was calculated from rates in text and Fig. 2, respectively. Bars $=1$ standard error; $n=$ number of experimental trials.

energy. Bugula stolonifera expended about $52 \%$ of its initial energy reserves to complete metamorphosis and about $1.6 \%$ per $\mathrm{h}$ while swimming. In contrast, $B$. neritina used only $28 \%$ of its initial reserves during metamorphosis and about $0.36 \%$ per h during swimming. Bugula simplex, which has a larva of intermediate size, expended about $40 \%$ of its initial energy reserves during completion of metamorphosis and about $0.84 \%$ per h during swimming (Table 3 ). Thus, assuming similar distributions of inert and labile energetic reserves in larvae of these species, small individuals expend more energy, relative to their size, in swimming and in metamorphosis than do large individuals, which agrees with the general trend found across animal phyla (e.g., Zeuthen, 1947, 1953; Pandian and Vernberg, 1987a, b, and several authors therein; Childress and Somero, 1990; Shilling and Manahan, 1994). This finding is in contrast to that reported for larvae of the echinoids Heliocidaris erythrogramma and H. tuberculata, where energetic output did not scale with larval size (Hoegh-Guldberg and Emlet, 1997).

Crawford's (1992) model demonstrated that the metabolic cost of swimming for small ciliated organisms increased with faster swimming speed and smaller size. Based on this relationship, it was predicted that small larvae would tend to swim slower to offset the increased metabolic cost. However, this was not the case for larvae of Bugula spp., since the smallest larva, that of B. stolonifera, actually swam the fastest. Given that larval swimming requires only $0.3 \%-1.5 \%$ of larval energy stores per hour, it is not surprising that $B$. stolonifera did not swim slower, as predicted from Crawford's (1992) model.

\section{Previous research on bryozoan larvae}

Orellana et al. (1996), working with larvae of the bryozoan Celleporella hyalina, did not detect a significant decrease in the amounts of protein or lipid after a 24-h period of larval swimming. In contrast to those results, my data for larvae of Bugula spp. document that carbon and nitrogen content decreased significantly during $24 \mathrm{~h}$ of larval swimming in most trials (Table 1). The exception was nitrogen content in larvae of $B$. neritina, which decreased in only one of four trials (Table 1). That nitrogen did not decrease consistently in larvae of $B$. neritina can be readily explained, as it is likely that lipid and carbohydrate reserves are utilized first during larval swimming, and that proteins are metabolized only after those reserves are depleted

Table 3

Costs during a maximum larval swimming period and metamorphosis in three species of Bugula

\begin{tabular}{|c|c|c|c|c|c|c|c|}
\hline \multirow[b]{2}{*}{ Species } & \multicolumn{3}{|c|}{ Calculated energy expenditure $(\mathrm{mJ})$} & \multirow[b]{2}{*}{ Energy content ${ }^{3}$} & \multicolumn{3}{|c|}{$\%$ of Endogenous reserves expended ${ }^{4}$} \\
\hline & Swim $\left(h^{-1}\right)$ & Max $\operatorname{swim}^{1}$ & Meta $^{2}$ & & Swim $\left(h^{-1}\right)$ & Max swim & Meta \\
\hline Bugula stolonifera & $0.08 \pm 0.01$ & $1.3 \pm 0.2$ & $2.6 \pm 0.2$ & $5.0 \pm 0.41$ & 1.60 & 26 & 52 \\
\hline Bugula simplex & $0.09 \pm 0.02$ & $1.7 \pm 0.3$ & $4.3 \pm 0.5$ & $10.7 \pm 0.28$ & 0.84 & 16 & 40 \\
\hline Bugula neritina & $0.12 \pm 0.02$ & $2.4 \pm 0.3$ & $9.5 \pm 1.5$ & $33.7 \pm 0.13$ & 0.36 & 7 & 28 \\
\hline
\end{tabular}

Values for swimming and metamorphosis were calculated based on the average oxyenthalpic equivalent of $468 \mathrm{~kJ} \mathrm{~mol}_{2}{ }^{-1}$ (Gnaiger, 1983). Metabolic rates are expressed as $\mathrm{mJ}$ ind $^{-1}$. Means \pm 1 standard error.

${ }^{1}$ Oxygen consumption rates were integrated over a maximal swimming duration which was estimated as the amount of time after which $50 \%$ of larvae lose the ability to complete metamorphosis ( $16 \mathrm{~h}, 19 \mathrm{~h}$, and $20 \mathrm{~h}$ for $B$. stolonifera, B. simplex, and B. neritina, respectively).

${ }^{2}$ Oxygen consumption values were integrated over the time it took $50 \%$ of the individuals in the experiment to complete metamorphosis $(38 \mathrm{~h}, 48 \mathrm{~h}$, and $48 \mathrm{~h}$ for B. stolonifera, B. simplex, and B. neritina, respectively).

${ }^{3}$ ( $\mathrm{mJ}$ per larva) calculated from elemental carbon using the equation: $\mathrm{kJ} \mathrm{g}$ biomass $^{-1}=10.28-66.26 * \mathrm{gC}$ (Gnaiger, 1984). Multiplying both sides of the equation by "g biomass" gives mJ. Biomass was estimated using the factor $1 \mu \mathrm{g} \mathrm{C}=2.5 \mu \mathrm{g}$ biomass (McEdward and Carson, 1987).

${ }^{4}$ Calculated by dividing the average energy (mJ) used for swimming (or metamorphosis) by the total energy content of the larva. 
(e.g., Emerson, 1967; Stickle, 1971). Because larvae of $B$. neritina have the lowest average specific metabolic rate of the species in this study (Fig. 4), one would predict that these larvae would swim the longest before metabolizing protein. In fact, values for the average percentage decrease of larval nitrogen during $24 \mathrm{~h}$ of swimming were $25 \%, 20 \%$, $12 \%$, and $6 \%$ for larvae of B. stolonifera, B. simplex, $B$. turrita, and $B$. neritina, respectively (calculated from Table 1; larvae in order of increasing size).

Jaeckle (1994) determined respiration rates for larvae of $B$. neritina collected from the same field site as those used in this study. He reported a mean respiration rate of $306 \pm$ 24.9 pmol $\mathrm{O}_{2}$ ind $^{-1} \mathrm{~h}^{-1}$ at $22^{\circ} \mathrm{C}$, compared to $249 \pm 45$ pmol $\mathrm{O}_{2}$ ind ${ }^{-1} \mathrm{~h}^{-1}$ measured in my study. The slightly higher rates reported by Jaeckle are expected, given that my experiments were carried out at $20^{\circ} \mathrm{C}, 2^{\circ} \mathrm{C}$ less than his experiments. He also measured larval energy content using the dichromate oxidation assay as described in Parsons et al. (1984) and modified by McEdward and Coulter (1987) for micro-samples. Jaeckle (1994) reports a total mean energy content of $15.24 \pm 1.33 \mathrm{~mJ} \mathrm{larva}^{-1}$ for larvae of B. neritina. This value is less than half as much as the $37.7 \pm 0.14 \mathrm{~mJ}$ ind $^{-1}$ measured here using elemental analysis. At present there is no way to resolve this discrepancy. However, given that oxygen demand during metamorphosis in my study was equivalent to an average of $9.5 \pm 1.5 \mathrm{~mJ}$, Jaeckle's estimate seems somewhat low in that metamorphosis alone would use $62 \%$ of a larva's internal energy reserves.

Sources of larval energetic reserves: realized contribution of dissolved organic material (DOM)

Energy used by larvae for swimming can potentially come from three sources: (1) endogenous reserves provided by the parent; (2) particulate organic matter consumed during feeding in the plankton; and (3) uptake and utilization of DOM. As larvae of Bugula spp. are anenteric and hence unable to ingest particulate food, their potential sources of energy are limited to parental ones and to DOM.

Recent work has demonstrated the uptake of DOM by larvae of several species of marine invertebrates (Manahan, 1989, 1990; Jaeckle and Manahan, 1989a, b; Welborn and Manahan, 1990; Ronnestad et al., 1992; Hoegh-Guldberg, 1994; Jaeckle, 1994, 1995a, b; Shilling and Manahan, 1990). It is known that embryos of $B$. neritina receive nutrients translocationally via a placenta-like organ during embryogenesis (Woollacott and Zimmer, 1975) and that larvae of $B$. neritina could potentially transport palmitic acid at a rate sufficient to account for from $21 \%$ to $72 \%$ of their metabolic demand (Jaeckle, 1994). Given the limited energy reserves in larvae of Bugula spp. for swimming and metamorphosis, it would be beneficial for them to also utilize energy from DOM, particularly if the larvae are advected from a site suitable for metamorphosis. However, my data suggest that as much as $95 \%-100 \%$ of the measured respiration rate could be accounted for by the estimated decline in elemental carbon and nitrogen. For example, calculations based on mean oxygen consumption indicate that larvae of $B$. neritina used $2.9 \mathrm{~mJ}$ larva $^{-1}$ during swimming for $24 \mathrm{~h}$ (assuming an oxyenthalpic equivalent of $468 \mathrm{KJ} \mathrm{mol} \mathrm{O}_{2}{ }^{-1}$ ), whereas calculations based on elemental analysis indicate that they used $3.2 \mathrm{~mJ} \mathrm{larva}^{-1}$, a mean difference of $-0.3 \mathrm{~mJ} \mathrm{larva}^{-1}$ (see Table 3 , footnote 3 , for assumptions used in calculation), suggesting that all of the respired $\mathrm{O}_{2}$ is the result of catabolism of endogenous carbon and nitrogen. Similar results are found for larvae of B. simplex, B. stolonifera, and B. turrita. These preliminary data suggest that larvae of Bugula spp. may not utilize significant amounts of DOM during their brief swimming phase. Clearly, more work is needed to determine the realized contribution of DOM to the nutrition of these and other larvae of marine invertebrates.

\section{Acknowledgments}

I thank Sherry Reed, Hugh Reichardt, and Dr. Mary E. Rice, all of the Smithsonian Marine Station at Fort Pierce, Fort Pierce, Florida, for their assistance in carrying out this research. Colleen Cavanaugh, Robert Woollacott (both of Harvard University), and Jan Pechenik (Tufts University) provided thoughtful discussions and comments which greatly improved the study. I extend my sincere gratitude to two anonymous reviewers whose suggestions also greatly improved the manuscript. Much appreciation goes to Edward Enos at the Marine Biological Laboratory and "Pinky" in Woods Hole, Massachusetts, for generously allowing us to collect animals from their respective facilities. I thank Wendy Lynn Wendt for editing the manuscript. Portions of this research were supported by a Smithsonian Fellowship and by a Grant-in-Aid of Research from Sigma Xi to Dean E. Wendt. This paper is contribution number 400 of the Smithsonian Marine Station, Fort Pierce, Florida.

\section{Literature Cited}

Childress, J. J., and G. N. Somero. 1990. Metabolic scaling: a new perspective based on scaling of glycolytic enzyme activities. Am. Zool. 30: 161-173.

Crawford, D. W. 1992. Metabolic cost of motility in planktonic protists: theoretical considerations on size scaling and swimming speed. $\mathrm{Mi}$ crob. Ecol. 24: 1-10.

Crisp, D. J. 1974. Energy relations of marine invertebrate larvae. Thalassia Jugosl. 10: 103-120.

Emerson, D. N. 1967. Carbohydrate oriented metabolism of Planorbis duplicatus (Mollusca: Planorbidae) during starvation. Comp. Biochem. Physiol. 22: 571-579.

Gnaiger, E. 1983. Calculation of energetic and biochemical equivalents of respiratory oxygen consumption. Pp. 337-345 in Polarographic Oxygen Sensors: Aquatic and Physiological Applications, E. Ganiger and H. Forstner, eds. Springer-Verlag, New York.

Gnaiger, E., and G. Bitterlich. 1984. Proximate biochemical composi- 
tion and caloric content calculated from elemental CHN analysis: a stoichiometric concept. Oecologica 62: 289-298.

Highsmith, R. C., and R. B. Emlet. 1986. Delayed metamorphosis: effect on growth and survival of juvenile sand dollars (Echinoidea: Clypeasteroida). Bull. Mar. Sci. 39: 347-361.

Hoegh-Guldberg, O. 1994. Uptake of dissolved organic matter by larval stage of the crown-of-thorn starfish Acanthaster planci. Mar. Biol. 120: $55-63$.

Hoegh-Guldberg, O., and R. B. Emlet. 1997. Energy use during the development of a lecithotrophic and planktotrophic echinoid. Biol. Bull. 192: 27-40.

Hunter, E., and N. Fusetani. 1996. Studies of the effects of larval swimming time on settlement, metamorphosis, and post-larval development of Bugula neritina (Cheilostomatida). Pp. 139-148 in Bryozoa In Space and Time, D. P. Gordon, A. M. Smith, and J. A. GrantMackie, eds. Colorographic International, Wellington, New Zealand.

Jaeckle, W. B. 1994. Rates of energy consumption and acquisition by lecithotrophic larvae of Bugula neritina (Bryozoa: Cheilstomata). Mar. Biol. 119: 517-523.

Jaeckle, W. B. 1995a. Variation in the size, energy content, and biochemical composition of invertebrate eggs: correlates to the mode of larval development. Pp. 49-78 in Ecology of Marine Invertebrate Larvae. L. R. McEdward, ed. CRC Press, Boca Raton, FL.

Jaeckle, W. B. 1995b. Transport and metabolism of alanine and palmitic acid by field-collected larvae of Tedania ignis (Porifera, Demospongiae): estimated consequences of limited label translocation. Biol. Bull. 189: 159-167.

Jaeckle, W. B., and D. T. Manahan. 1989a. Amino acid uptake and metabolism by larvae of the marine worm Urechis caupo (Echiura), a new species in axenic culture. Biol. Bull. 176: 317-326.

Jaeckle, W. B., and D. T. Manahan. 1989b. Feeding by a "nonfeeding larva": uptake of dissolved amino acids from seawater by lecithotrophic larvae of the gastropod Haliotis rufescens. Mar. Biol. 103: 87-89.

Jarret, J. N., and J. A. Pechenik. 1997. Temporal variation in cyprid quality and juvenile growth capacity for an intertidal barnacle. Ecology 78: $1262-1265$.

Levin, L. A., and T. S. Bridges. 1995. Pattern and diversity in reproduction and development. Pp. 1-48 in Ecology of Marine Invertebrate Larvae. L. R. McEdward, ed. CRC Press, Boca Raton, FL.

Lucas, M. I., G. Walker, D. L. Holland, and D. J. Crisp. 1979. An energy budget for the free-swimming and metamorphosing larva of Balanus balanoides (Crustacea: Cirripedia). Mar. Biol. 55: 221-229.

Manahan, D. T. 1989. Amino acid fluxes to and from seawater in axenic veliger larvae of a bivalve (Crassostrea gigas). Mar. Ecol. Prog. Ser. 53: $247-255$.

Manahan, D. T. 1990. Adaptations by invertebrate larvae for nutrient acquisition from seawater. Am. Zool. 30: 147-160.

McCarthy, J. J., C. Garside, and J. L. Nevins. 1999. Nitrogen dynamics during the Arabian Sea Northeast Monsoon. Deep-Sea Res. II 46: 1623-1664.

McEdward, L. R., and S. F. Carson. 1987. Variation in organic content and its relationship with egg size in the starfish Solaster stimpsoni. Mar. Ecol. Prog. Ser. 37: 159-169.

McEdward, L. R., and L. K. Coulter. 1987. Egg volume and energetic content are not correlated among sibling offspring of starfish: implications for life-history theory. Evolution. 41: 914-917.

Nielsen, C. 1981. On morphology and reproduction of Hippodiplosia insculpta and Fenestrulina malusii (Bryozoa, Cheilostomata). Ophelia 20: $91-125$.

Orellana, M. C., and J. M. Cancino. 1991. The effects of delaying larval settlement on metamorphosis and early colonial growth in Celleporella hyalina (Bryozoa: Cheilostomata). Pp. 309-316 in Bryozoa Living and Fossil, F. P. Bigey, ed. Bull. Soc. Sci. Nat. Ouest Fr., Mem. HS1. Saint-Herblain, Nantes, France.
Orellana, M. C., J. M. Cancino, and R. N. Hughes. 1996. Is settlement in lecithotrophic bryozoan larvae constrained by energy reserves? Pp. 221-226 in Bryozoans in Space and Time, D. P. Gordon, A. M. Smith, and J. A. Grant-Mackie, eds. NIWA (Nat. Inst. Water Atmospheric Res.), Wellington, NZ.

Pandian, T. J., and F. J. Vernberg, eds. 1987a. Animal Energetics: Protozoa Through Insecta. Vol 1. Academic Press, San Diego, CA.

Pandian, T. J., and F. J. Vernberg, eds. 1987b. Animal Energetics: Bivalvia Through Reptillia. Vol 2. Academic Press, San Diego, CA.

Parsons, T. R., Y. Maita, and C. M. Lalli. 1984. A Manual of Chemical and Biological Methods for Seawater Analysis. Pergamon Press, New York. Pp. 63-66.

Pechenik, J. A. 1980. Growth and energy balance during the larval lives of three prosobranch gastropods. J. Exp. Mar. Biol. Ecol. 44: 1-28.

Pechenik, J. A. 1990. Delayed metamorphosis of benthic marine invertebrates: Does it occur? Is there a price to pay? Ophelia 32: 63-94.

Pechenik, J. A., and T. R. Cerulli. 1991. Influence of delayed metamorphosis on survival, growth, and reproduction of the polychaete Capitella sp. I. J. Exp. Mar. Biol. Ecol. 151: 17-27.

Pechenik, J. A., and B. Fried. 1995. Effect of temperature on survival and infectivity of Echinostoma trivolvis cercariae: a test of the energy limitation hypothesis. Parasitology. 111: 373-378.

Pechenik, J. A., D. Rittschof, and A. R. Schmidt. 1993. Influence of delayed metamorphosis on survival and growth of juvenile barnacles Balanus amphitrite. Mar. Biol. 115: 287-294.

Pechenik, J. A., D. E. Wendt, and J. N. Jarret. 1998. Metamorphosis is not a new beginning. BioScience 48: 901-909.

Pires, A., and R. M. Woollacott. 1997. Serotonin and dopamine have opposite effects on phototaxis in larvae of the bryozoan Bugula neritina. Biol. Bull. 192: 399-409.

Qian, P-Y., L. R. McEdward, and F-S. Chia. 1990. Effects of delayed settlement on survival, growth, and reproduction in the spionid polychaete, Polydora ligni. Int. J. Invertebr. Reprod. Dev. 18: 147152.

Reed, C. G., and R. M. Woollacott. 1982. Mechanisms of rapid morphogenetic movements in the metamorphosis of the bryozoan Bugula neritina (Cheilostomata, Cellularioidea). I Attachment to the substratum. J. Morphol. 172: 335-348.

Reed, C. G., and R. M. Woollacott. 1983. Mechanisms of rapid morphogenetic movements in the metamorphosis of the bryozoan Bugula neritina (Cheilostomata, Cellularioidea). II The role of dynamic assemblages of microfilaments in the pallial epithelium. J. Morphol. 177: 127-143.

Richmond, R. H. 1987. Energetics, competency, and long-distance dispersal of planula larvae of the coral Pocillopora damicornis. Mar. Biol. 93: $527-533$

Richmond, R. H. 1988. Competency and dispersal potential of planula larvae of a spawning versus a brooding coral. Proc. 6th Int. Coral Reef Symposium 2: 827-831.

Ronnestad, I., H. J. Fyhn, and K. Gravningen. 1992. The importance of free amino acids to the energy metabolism of eggs and larvae of turbot (Scophthalmus maximus). Mar. Biol. 114: 517-525.

Ryland, J. S. 1974. Behaviour, settlement and metamorphosis of bryozoan larvae: a review. Thalassia Jugosl. 10: 239-262.

Shilling, F. M., and D. T. Manahan. 1990. Energetics of early marine development for the sea urchins Strongylocentrotus purpuratus and Lytechinus pictus and the crustacean Artemia sp. Mar. Biol. 106: $119-128$.

Shilling, F. M., and D. T. Manahan. 1994. Energy metabolism and amino acid transport during early development of Antarctic and temperate echinoderms. Biol. Bull. 187: 398-407.

Stickle, W. B. 1971. The metabolic effects of starving Thais lamellosa immediately after spawning. Comp. Biochem. Physiol. 40A: 627-634. Strathmann, M. F. 1987. Reproduction and Development of Marine 
Invertebrates of the Northern Pacific Coast. University of Washington Press, Seattle, WA.

Strathmann, R. R. 1974. Introduction to function and adaptation in echinoderm larvae. Thalassia Jugosl. 10: 321-339.

Vogel, S. 1994. Life in Moving Fluids. Princeton University Press, Princeton, NJ.

Weast, R. C., and M. J. Astle. 1980. CRC Handbook of Chemistry and Physics, 61st ed. CRC Press, Boca Raton, FL.

Welborn, J. R., and D. T. Manahan. 1990. Direct measurements of sugar uptake from seawater into molluscan larvae. Mar. Ecol. Prog. Ser. 65: 233-239.

Wendt, D. E. 1996. Effect of larval swimming duration on success of metamorphosis and size of the ancestrular lophophore in Bugula neritina (Bryozoa). Biol. Bull. 191: 224-233.

Wendt, D. E. 1998. Effect of larval swimming duration on growth and reproduction of Bugula neritina (Bryozoa) under field conditions. Biol. Bull. 195: 126-135.

Wendt, D. E., and R. M. Woollacott. 1995. Induction of larval settlement by $\mathrm{KCl}$ in three species of Bugula (Bryozoa). Invertebr. Biol. 114 345-351.

Wendt, D. E., and R. M. Woollacott. 1999. Ontogenies of larval phototaxis and metamorphic competence in Bugula spp. (Bryozoa). Invertebr. Biol. 118: 75-84.

Wilson, J. R., and P. L. Harrison. 1998. Settlement-competency periods of larvae of three species of scleractinian corals. Mar. Biol. 131: $339-345$.
Woollacott, R. M., and R. L. Zimmer. 1971. Attachment and metamorphosis of the Cheilo-ctenostome bryozoan Bugula neritina (Linné) J. Morphol. 134: 351-382.

Woollacott, R. M., and R. L. Zimmer. 1972. Origin and structure of the brood chamber in Bugula neritina (Bryozoa). Mar. Biol. 16: 165170 .

Woollacott, R. M., and R. L. Zimmer. 1975. A simplified placenta-like system for the transport of extraembryonic nutrients during embryogenesis of Bugula neritina. J. Morphol. 147: 355-377.

Woollacott, R. M., and R. L. Zimmer. 1978. Metamorphosis of cellularioid bryozoans. Pp. 49-63 in Settlement and Metamorphosis of Marine Invertebrate Larvae. F.-S. Chia and M. E. Rice, eds. Elsevier North-Holland, New York.

Woollacott, R. M., J. A. Pechenik, and K. M. Imbalzano. 1989. Effects of duration of larval swimming period on early colony development in Bugula stolonifera (Bryozoa: Cheilostomata). Mar. Biol. 102: $57-63$.

Zaslow, R. B-D., and Y. Benayahu. 1996. Longevity, competence and energetic content in planulae of the soft coral Heteroxenia fuscescens. J. Exp. Mar. Biol. Ecol. 206: 55-68.

Zeuthen, E. 1947. Body size and metabolic rate in the animal kingdom with special regard to the marine microfauna. C. R. Trav. Lab. Carlsberg. Ser. Chim. 26: 17-161.

Zeuthen, E. 1953. Oxygen uptake as related to body size in organisms. Q. Rev. Biol. 28: 1-12. 